\title{
Particle Size Reduction
}

National Cancer Institute

\section{Source}

National Cancer Institute. Particle Size Reduction. NCI Thesaurus. Code C84386.

The mechanical process of breaking particles into smaller pieces via one or more particle size reduction mechanisms. Milling is the most common process used. 